\title{
BMJ Open Association between neighbourhood deprivation, fetal growth, small-for- gestational age and preterm birth: a population-based prospective cohort study
}

\author{
Dionne V Gootjes (D) , , ${ }^{1,2}$ Anke G Posthumus, ${ }^{1,2}$ Vincent W V Jaddoe, ${ }^{2,3}$ \\ Eric A P Steegers ${ }^{1,2}$
}

To cite: Gootjes DV, Posthumus AG, Jaddoe VWV, et al. Association between neighbourhood deprivation, fetal growth, small-for-gestational age and preterm birth: a population-based prospective cohort study. BMJ Open 2021;11:e049075. doi:10.1136/ bmjopen-2021-049075

- Prepublication history and additional supplemental material for this paper are available online. To view these files, please visit the journal online (http://dx.doi.org/10.1136/ bmjopen-2021-049075).

Received 14 January 2021 Accepted 18 0ctober 2021

D) Check for updates

(c) Author(s) (or their employer(s)) 2021. Re-use permitted under CC BY-NC. No commercial re-use. See rights and permissions. Published by BMJ.

1Department of Obstetrics and Gynaecology, Division of Obstetrics and Prenatal Medicine, Erasmus MC, Rotterdam, The Netherlands ${ }^{2}$ Generation R Study Group, Erasmus MC, Rotterdam, The Netherlands

${ }^{3}$ Department of Paediatrics, Erasmus MC, Rotterdam, The Netherlands

Correspondence to Dr Dionne V Gootjes; d.gootjes@erasmusmc.nl

\section{ABSTRACT}

Objective To study the associations between neighbourhood deprivation and fetal growth, including growth in the first trimester, and adverse pregnancy outcomes.

Design Prospective cohort study.

Setting The Netherlands, Rotterdam.

Participants 8617 live singleton births from the Generation R cohort study.

Exposition Living in a deprived neighbourhood. Main outcome measures Fetal growth trajectories of head circumference, weight and length.

Secondary outcomes measures Small-for-gestational age (SGA) and preterm birth (PTB).

Results Neighbourhood deprivation was not associated with first trimester growth. However, a higher neighbourhood status score (less deprivation) was associated with increased fetal growth in the second and third trimesters (eg, estimated fetal weight; adjusted regression coefficient $0.04,95 \% \mathrm{Cl} 0.02$ to 0.06 ). Less deprivation was also associated with decreased odds of SGA (adjusted OR 0.91, 95\% $\mathrm{Cl} 0.86$ to $0.97, \mathrm{p}=0.01$ ) and PTB (adjusted OR 0.89, 95\% Cl 0.82 to $0.96, p=0.01$ ). Conclusions We found an association between neighbourhood deprivation and fetal growth in the second and third trimester pregnancy, but not with first trimester growth. Less neighbourhood deprivation is associated with lower odds of adverse pregnancy outcomes. The associations remained after adjustment for individual-level risk factors. This supports the hypothesis that living in a deprived neighbourhood acts as an independent risk factor for fetal growth and adverse pregnancy outcomes, above and beyond individual risk factors.

\section{INTRODUCTION}

A low individual socioeconomic status (SES) is associated with adverse health outcomes. ${ }^{1}$ Additionally, there is accumulating evidence that the SES of the neighbourhood a person lives in also associated with health outcomes. ${ }^{2}$ This is also the case for pregnancy: both individual SES and living in a deprived
Strengths and limitations of this study

- This study is performed within a large multiethnic cohort.

- The Generation R study population is not completely representative of the Dutch population.

- Associations were adjusted for a wide range of relevant individual-level risk factors, which allows the isolation of a neighbourhood-specific effect as best as possible.

neighbourhood are acknowledged risk factors for adverse pregnancy outcomes. ${ }^{3-5}$

Recent evidence shows that other factors, such as maternal nutrition and lifestyle, already affect pregnancy from the first trimester onwards. ${ }^{6-9}$ Gaining a better understanding of modifiable factors that influence pregnancy from the earliest phase onwards is important: first since impaired development during the first trimester of pregnancy is associated with adverse pregnancy outcomes ${ }^{6}$; and second, in line with the DOHaD paradigm (Developmental Origin of Health and Disease), impaired development in pregnancy and adverse pregnancy outcomes are associated with an increased risk of noncommunicable diseases in adult life, such as cardiovascular disease. ${ }^{10}$ If impaired early fetal development could be prevented or recognised, this would enable the prevention of both short-term and long-term adverse outcomes.

Living in a deprived neighbourhood is known to be a risk factor for adverse health outcomes, above and beyond the association with individual risk factors such as inadequate nutrition and lifestyle behaviours. Living in a deprived neighbourhood may lead to exposure to a suboptimal environment, with 
higher rates of air pollution, less access to facilities such as a green environment to walk in, fewer nearby healthcare facilities and little possibility to purchase healthy food nearby. Lastly, living in a deprived neighbourhood is acknowledged as a source of chronic stress, which is associated with increased cortisol levels, and thereby acts as an independent risk factor for adverse health outcomes. ${ }^{11} 12$ It is however unknown whether living in a deprived neighbourhood is also associated with adverse pregnancy outcomes and (early) fetal development. Therefore, the aim of this study was to investigate the associations between neighbourhood deprivation, fetal growth, including growth in the first trimester, and adverse pregnancy outcomes.

\section{METHODS \\ Design}

This study was embedded in the Generation $\mathrm{R}$ (Rotterdam) study, a population-based prospective cohort study. ${ }^{13}$ Pregnant women living in the area of Rotterdam, the Netherlands, with an expected delivery date between April 2002 and January 2006 were invited to participate in this study. The 9778 mothers enrolled in the study gave birth to 9749 live born children. Of these mothers, $91 \%$ $(\mathrm{n}=8879)$ were prenatally enrolled in the study, giving birth to 8976 children. Our aim was to investigate growth trajectories and adverse pregnancy outcomes of ongoing singleton pregnancies. We excluded the following pregnancies: twin pregnancies, terminated pregnancies, intrauterine deaths and pregnancies without information on

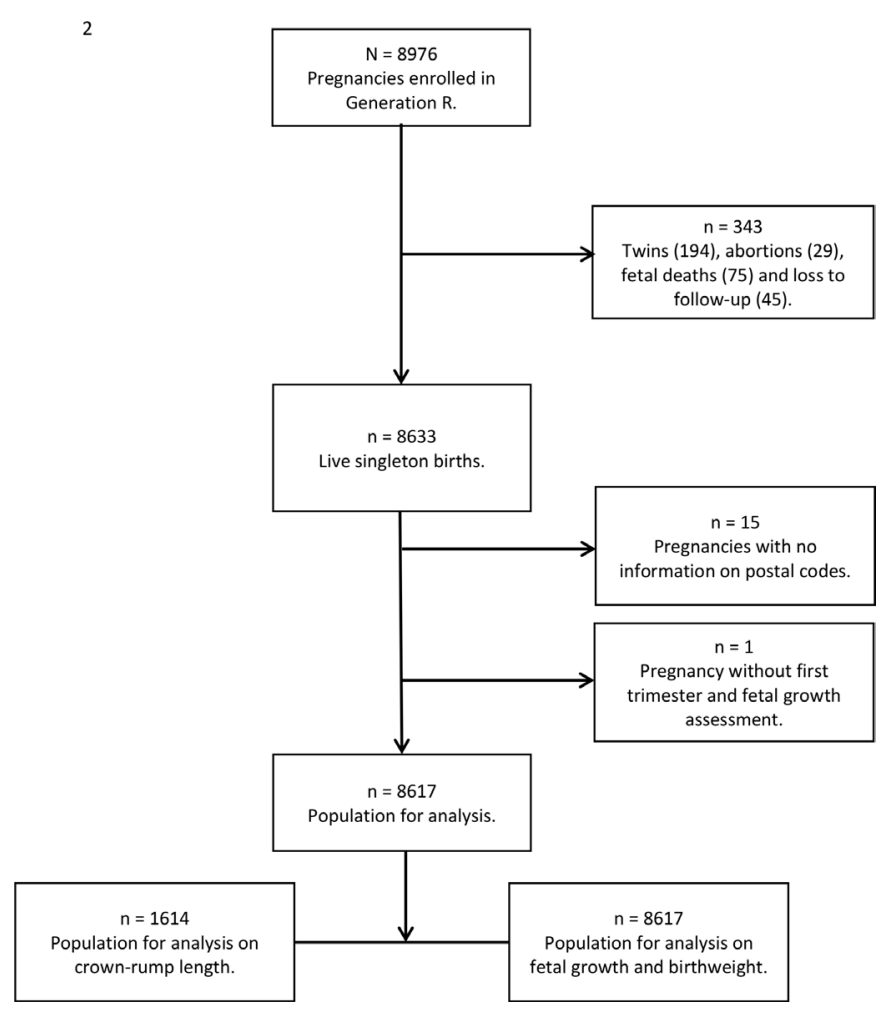

Figure 1 Flow chart of the study population. area of residence or ultrasound data (figure 1). Written informed consent was obtained from all participants.

\section{Patient and public involvement}

This research was done without patient involvement. Patients were not invited to comment on the study design and were not consulted to develop patient relevant outcomes or interpret the results. Patients were not invited to contribute to the writing or editing of this document for readability or accuracy.

\section{MATERIALS}

\section{Neighbourhood deprivation}

We used area-based status scores as a proxy for neighbourhood deprivation, which were made available by the Netherlands Institute for Social Research. ${ }^{14}$ The scores are matched on four-digit postcodes and are based on mean household income, proportion of population with low income, proportion of population with low educational level and proportion of population without paid work. The scores are determined every 4 years and a more negative score represents a lower SES. The status scores used in this study were calculated in 2002 and 2006. The correlation between the status scores in 2002 and 2006 was very high: $r=0.97$. To assign the status scores in the best possible way, pregnancies in 2002 and 2003 were allocated with the status score of 2002. For pregnancies in 2005 and 2006, the status score of 2006 was assigned. For pregnancies in 2004, the average score of 2002 and 2006 was assigned.

\section{Pregnancy dating}

Gestational age is the most important determinant of fetal growth, so precise dating of the pregnancy is important. It has long been assumed that embryonic growth in the first trimester of pregnancy is universal. This is the rationale behind the current practice of pregnancy dating using the crown-rump length (CRL), if the gestational age is less than 12 weeks and 5 days and the CRL measurement is smaller than $65 \mathrm{~mm} .{ }^{15}$ However, study findings suggest that first trimester growth is not uniform. ${ }^{16}$ Therefore, in our analyses with CRL measurements as the outcome of interest, pregnancy dating was not based on the CRL but on the known and reliable last menstrual period (LMP) in case of a regular menstrual cycle (28 44 days). ${ }^{6}$ All other cases were excluded for that particular analyses of CRL. LMP was obtained from the referral letter and confirmed at enrolment. Additional information on regularity and cycle duration was obtained through questionnaires. When the gestational age was more than 12 weeks and 5 days, or the biparietal diameter (BPD) was larger than $23 \mathrm{~mm}$, pregnancy dating was performed using the BPD.

\section{Growth parameters and adverse pregnancy outcomes}

The aim of the study was to focus on fetal outcomes, in terms of growth and development. The selected outcomes were carefully chosen from the 'Big 4 conditions', which 
are specifically defined conditions that precede perinatal mortality in $85 \%$ of all cases, namely small-for-gestational age (SGA; birth weight $<10$ th percentile for gestational age), preterm birth (PTB; birth $<37$ weeks of gestation), congenital disorders and/or low Apgar score $(<7$ after $5 \mathrm{~min}) .{ }^{1718}$ Due to the low number of cases with congenital disorders within the Generation R population and the susceptibility for Apgar score to be affected by the course of delivery, which may confound the effect of neighbourhood deprivation during pregnancy, we selected the other two major morbidity factors as outcome for this study.

Ultrasound assessments were carried out during visits to one of the research centres and took place in early (median 13.2 weeks of gestation), mid (median 20.5 weeks of gestation) and late (median 30.3 weeks of gestation) pregnancy. Growth parameters included the CRL, head circumference (HC), femur length (FL), abdominal circumference (AC), estimated fetal weight (EFW) and birth weight. EFW was calculated using the Hadlock formula with parameters $\mathrm{AC}, \mathrm{HC}$ and $\mathrm{FL}$ (in $\mathrm{cm}$ ): $\mathrm{EFW}=10^{\wedge}(1.326-$ $0.00326 * \mathrm{AC} * \mathrm{FL}+0.0107 * \mathrm{HC}+0.0438 * \mathrm{AC}+0.158 * \mathrm{FL})$ (online supplemental file 1). ${ }^{19}$ Gestational age-adjusted SD scores (SDS) were constructed for all growth measurements. ${ }^{20}$ The SDS for birth weight were constructed using growth standards from Niklasson $e t a l,{ }^{21}$ which were adjusted for gestational age at the time of birth and sex of the neonate. Measurements were performed using uniform ultrasound procedures and were executed with the Aloka Model SSD-1700 (Tokyo, Japan) or the ATL Philips Model HDI 5000 (Seattle, Washington, USA). Reproducibility of these measurements has been assessed and described previously. ${ }^{22} 23$

SGA at birth was defined as sex-adjusted and gestational age-adjusted birth weight below the 10th percentile $(<-1.40$ SDS) in the study cohort. PTB was defined as gestational age of $<37$ weeks at delivery.

\section{Covariates}

Information on maternal age, educational level, ethnicity and maternal folic acid supplement use was obtained at enrolment. ${ }^{13}$ All study materials such as questionnaires, newsletters, websites and information folders were available in three languages (Dutch, English and Turkish). Furthermore, staff from different ethnic backgrounds were available and verbally translated these materials into Arabic, French and Portuguese. As such, the study staff were able to communicate with all participants.

Ethnicity of participating mothers was defined according to the classification of Statistics Netherlands and was categorised into Dutch and other Western (European, American and Oceanian); Turkish and Moroccan; African (Cape Verdean, other African, Surinamese-Creole and Dutch Antillean); and Asian (Indonesian, other Asian and Surinamese-Hindu), according to the largest ethnic groups in our study population and similarities in skin colour and cultural background. In sensitivity analyses, the following classification was used: Dutch, European, Turkish,
Moroccan, African, Dutch Antillean, Cape Verdean, Indonesian, Surinamese-Creole, Surinamese-Hindu, Surinamese-unspecified, American Western, American non-Western, Asia Western, Asia non-Western and Oceanian. ${ }^{13}$ Information about smoking, alcohol consumption and caffeine intake was assessed by questionnaires in each trimester. Maternal prepregnancy body mass index (BMI) was calculated from the reported height $(\mathrm{cm})$ and weight $(\mathrm{kg})$ on the questionnaires. Information about pregnancy complications, mode of delivery and childhood sex, gestational age, and weight and length at birth was obtained from the medical records. ${ }^{20}{ }^{21}$ Complications in a previous pregnancy were defined as gestational diabetes, preeclampsia, thrombosis in the arm or leg, pulmonary embolism, solutio placentae, premature rupture of membranes, contractions before 37 weeks of pregnancy or pregnancy-induced hypertension. We selected potential confounding variables based on their associations with the outcomes of interest in order to isolate a neighbourhood-specific effect.

\section{Statistical analysis}

First, we examined the differences between quartiles of neighbourhood deprivation for maternal characteristics, first trimester growth and fetal growth and adverse pregnancy outcomes. Second, we examined the associations of neighbourhood deprivation with fetal growth patterns using unbalanced repeated measurement regression models. ${ }^{24}$ We included neighbourhood deprivation in these models as intercept and as interaction term with gestational age to estimate fetal growth rates over time. ${ }^{24}$ Third, we assessed the associations of neighbourhood deprivation with the risk of adverse pregnancy outcomes using multiple logistic regression models. In the basic model, the crude association between neighbourhood deprivation and the outcome of interest was investigated. The adjusted model included maternal age, maternal educational level, smoking, alcohol use, folic acid supplement use, ethnicity, parity, prepregnancy BMI and fetal sex. We tested the interaction between neighbourhood deprivation and complications in previous pregnancy in the regression models. Fourth, we examined the associations of neighbourhood deprivation with fetal growth in gestational age-adjusted SDS in each pregnancy period using linear regression models with the same adjustment models. We performed several sensitivity analyses. In the first analysis, we performed multilevel regression analysis in order to adjust for potential clustering between the different neighbourhoods. In the second analysis, we repeated the analyses with all 1614 available CRL measurements, compared with the analyses with only CRL measurements below 12 weeks of gestational age. ${ }^{62}$ A third sensitivity analysis was performed to determine to which extent the inclusion of pregnancies with an impaired fetal development, possibly due to placental dysfunction, influenced our 
results. Therefore we performed analyses excluding SGA-born babies. Fourth, analyses were additionally adjusted for household income. Also, we repeated the analyses with the different classifications of ethnicity, described in the 'Covariates' section. Lastly, we checked whether the presence of maternal hypertensive disorders affected the analyses on SGA.

Our main outcome was fetal growth, in terms of HC, length and weight. Post-hoc power for 0.1 SD difference in fetal growth with an alpha of 0.05 for a study group of 8000 (this study population 8617) participants is $99.4 \%$. We used multiple imputation for missing values of covariates according to Markov Chain Monte Carlo method (details given in online supplemental file 2). ${ }^{25}$ The percentage of missing data was $<10 \%$, except for smoking (12.7\%), alcohol use (13.8\%) and folic acid supplement use $(25.9 \%)$. Five imputed data sets were created and pooled for analyses. A sensitivity analysis was performed to observe differences in observed and expected values of confounders before and after imputation. Tests for trend were based on regression models with neighbourhood deprivation as a continuous variable. We checked whether the regression models were linear using scatterplots of the dependent variable plotted against the independent variable. ${ }^{26}$ Residuals were normally distributed as assessed by visual inspection of a normal probability plot. We tested for multicollinearity using the tolerance statistics. As tolerance was $>0.20$ for all variables in our models, there were no problems of multicollinearity. The repeated measurement analysis was performed using Statistical Analysis System V.9.3, including the Proc Mixed module for unbalanced repeated measurements. All other analyses were performed using Statistical Package of Social Sciences V.21.0 for Windows.

\section{RESULTS}

A total of 8976 pregnancies were included in the Generation R study. In total, we included 8617 pregnancies for analyses (figure 1 ). Table 1 depicts the baseline characteristics of both the total study population and the population stratified according to quartiles of neighbourhood deprivation. Women in the total study population were on average 29.6 years old with a median BMI of $22.8 \mathrm{~kg} / \mathrm{m}^{2}$. Stratification of the population in deprivation quartiles revealed that 2170 women $(25.2 \%)$ lived in a neighbourhood with the most deprivation, that is, lowest status score, and 2149 (24.9\%) lived in the least deprived neighbourhoods, that is, the highest status score. When comparing women in the most deprived neighbourhoods with those in the least deprived neighbourhoods, fewer women were highly educated $(23.7 \%$ vs $62.8 \%$; $\mathrm{p}<0.001)$, more women continued smoking in pregnancy $(22.3 \%$ vs $11.9 \% ; \mathrm{p}<0.001)$ and fewer women used any folic acid supplements $(20.0 \%$ vs $49.7 \%$, respectively; $\mathrm{p}<0.001)$ (table 1). In online supplemental table 1, the fetal growth parameters and adverse pregnancy outcomes stratified by quartile of neighbourhood deprivation are presented. Overall, growth parameters are smaller in the most deprived neighbourhoods compared with the least deprived neighbourhoods (eg, $-0.07 \mathrm{SD}$ vs $0.15 \mathrm{SD}, \mathrm{EFW}$ in the third trimester of pregnancy, respectively).

\section{Neighbourhood deprivation and fetal growth}

Figure 2 shows the results of the longitudinal analyses on the association between quartiles of neighbourhood deprivation and fetal HC, length and weight growth patterns from mid-pregnancy onwards. It shows that compared with the least deprived neighbourhoods, in the more deprived neighbourhoods fetal HC, length and weight were smaller (for all measures, the gestational age-dependent effect of neighbourhood deprivation on fetal growth showed a significant value $<0.05)$. Regression coefficients for gestational age-independent and gestational age-dependent effects are given in online supplemental table 2.

The associations of neighbourhood deprivation with first, second and third trimester fetal growth based on regular linear regression models are shown in online supplemental figure 1. In both the basic and adjusted analyses, a positive association between neighbourhood deprivation and $\mathrm{AC}$ was present (difference in $\mathrm{AC}$ in the adjusted model, 0.03 SDS (95\% CI 0.01 to 0.05 , $\mathrm{p}=0.002$ ) per one-unit increase in neighbourhood status score). In the third trimester of pregnancy, a positive association was found for HC, AC and EFW (adjusted model difference of 0.04 SDS (95\% CI 0.02 to $0.05, \mathrm{p}<0.001$ ), 0.04 SDS $(95 \%$ CI 0.03 to $0.06, \mathrm{p}<0.001)$ and 0.04 SDS (95\% CI 0.03 to $0.06, \mathrm{p}<0.001)$ per one-unit increase in neighbourhood status score, respectively). Overall, there is a dose-response-like association between neighbourhood deprivation and fetal growth, with stronger associations in the most deprived neighbourhoods compared with the least deprived neighbourhoods.

Effect modification analyses showed a significant interaction between neighbourhood deprivation and complications in previous pregnancies for PTB (online supplemental table 3 ). The associations between neighbourhood deprivation and fetal growth and adverse pregnancy outcomes were non-significant in the group with a complication in a previous pregnancy (eg, $\mathrm{HC}$ in late pregnancy attenuates from 0.06 SDS (95\% CI 0.05 to 0.08 , $\mathrm{p}<0.001)$ to 0.03 SDS $(95 \% \mathrm{CI}-0.05$ to $0.11, \mathrm{p}=0.50)$ per one-unit increase in neighbourhood status score) (online supplemental table 4 ).

\section{Neighbourhood deprivation and adverse pregnancy outcomes}

The results of the regression analysis on neighbourhood deprivation and adverse pregnancy outcomes are presented in table 2. Living in a more affluent neighbourhood was inversely associated with the odds of delivering an SGA neonate (adjusted model, OR 0.91, $95 \%$ CI 0.86 to $0.97, \mathrm{p}=0.01$ ), independent of maternal 
Table 1 Baseline characteristics of the study population, stratified according to quartile of neighbourhood deprivation

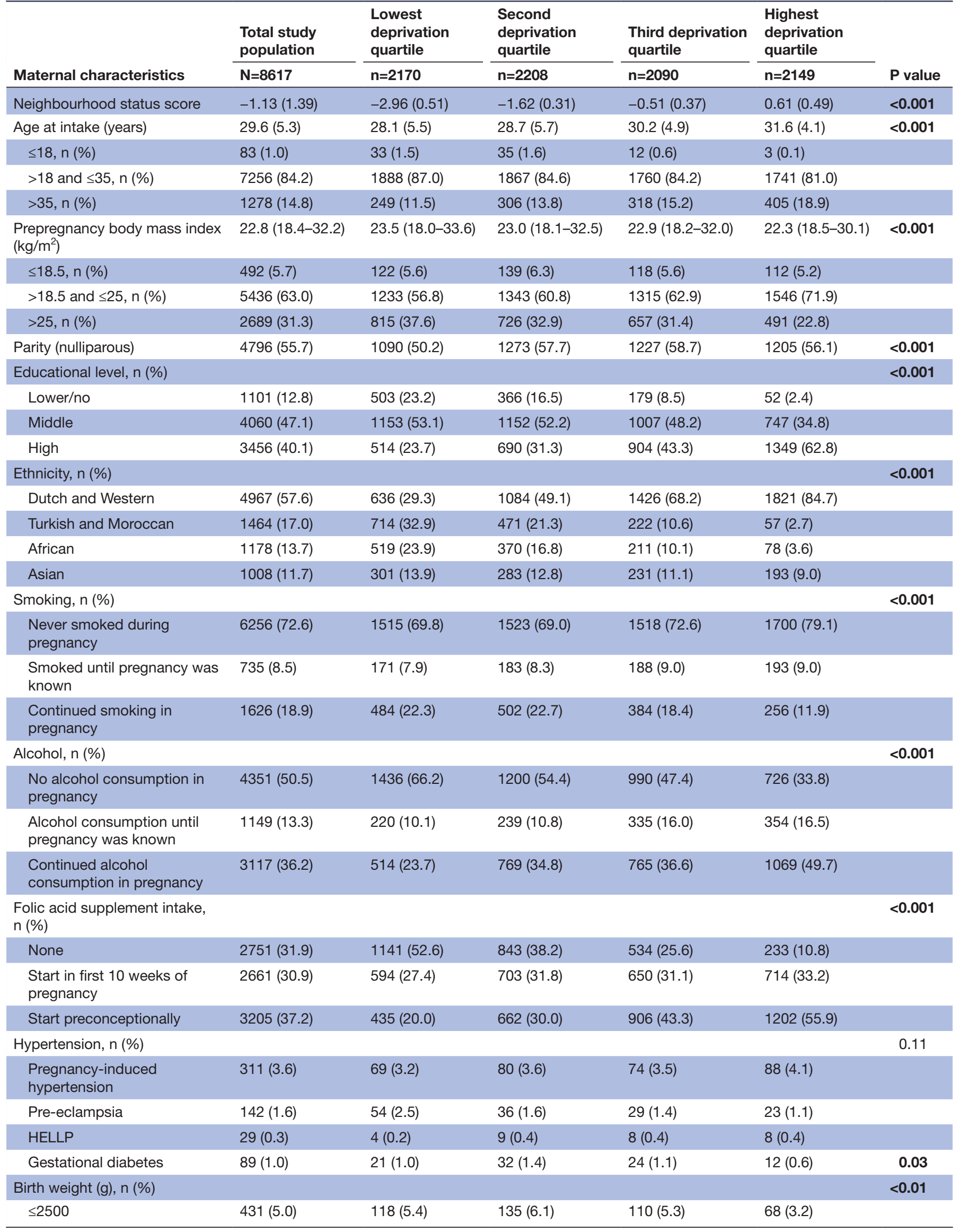


Table 1 Continued

\begin{tabular}{|c|c|c|c|c|c|c|}
\hline & $\begin{array}{l}\text { Total study } \\
\text { population }\end{array}$ & $\begin{array}{l}\text { Lowest } \\
\text { deprivation } \\
\text { quartile }\end{array}$ & $\begin{array}{l}\text { Second } \\
\text { deprivation } \\
\text { quartile }\end{array}$ & $\begin{array}{l}\text { Third deprivation } \\
\text { quartile }\end{array}$ & $\begin{array}{l}\text { Highest } \\
\text { deprivation } \\
\text { quartile }\end{array}$ & \\
\hline Maternal characteristics & $\mathrm{N}=8617$ & $\mathrm{n}=\mathbf{2 1 7 0}$ & $\mathrm{n}=2208$ & $\mathrm{n}=\mathbf{2 0 9 0}$ & $n=2149$ & $P$ value \\
\hline$>2500$ and $\leq 4000$ & 7017 (81.4) & $1815(83.6)$ & $1786(80.9)$ & $1683(80.5)$ & $1733(80.6)$ & \\
\hline$>4000$ & 1169 (13.6) & $237(11.0)$ & $287(13.0)$ & $297(14.2)$ & 348 (16.2) & \\
\hline $\begin{array}{l}\text { Gestational age at delivery } \\
\text { (weeks), } \mathrm{n}(\%)\end{array}$ & & & & & & 0.01 \\
\hline$<37$ & $492(5.7)$ & $134(6.2)$ & $152(6.9)$ & $117(5.6)$ & $89(4.1)$ & \\
\hline $37-42$ & 7697 (89.3) & 1937 (89.3) & 1947 (88.2) & $1859(88.9)$ & $1954(90.9)$ & \\
\hline$>42$ & $428(5.0)$ & $99(4.5)$ & $109(4.9)$ & $114(5.5)$ & $106(5.0)$ & \\
\hline $\begin{array}{l}\text { Complications in a previous } \\
\text { pregnancy, } \mathrm{n}(\%)\end{array}$ & $606(7.0)$ & $153(7.1)$ & $149(6.7)$ & $132(6.3)$ & $172(8.0)$ & 0.13 \\
\hline
\end{tabular}

Data are presented as $\mathrm{n}(\%)$, mean (SD) or median with the $90 \%$ range.

$P$-value in bold: statistically significant $p$-value $<0.05$.

Differences in baseline characteristics were tested using analysis of variance, Kruskal-Wallis test and $\chi^{2}$ test.

Confounders are imputed. Non-imputed percentages are valid percentages.

HELLP, Hemolysis, elevated liver enzymes and low platelets syndrome.

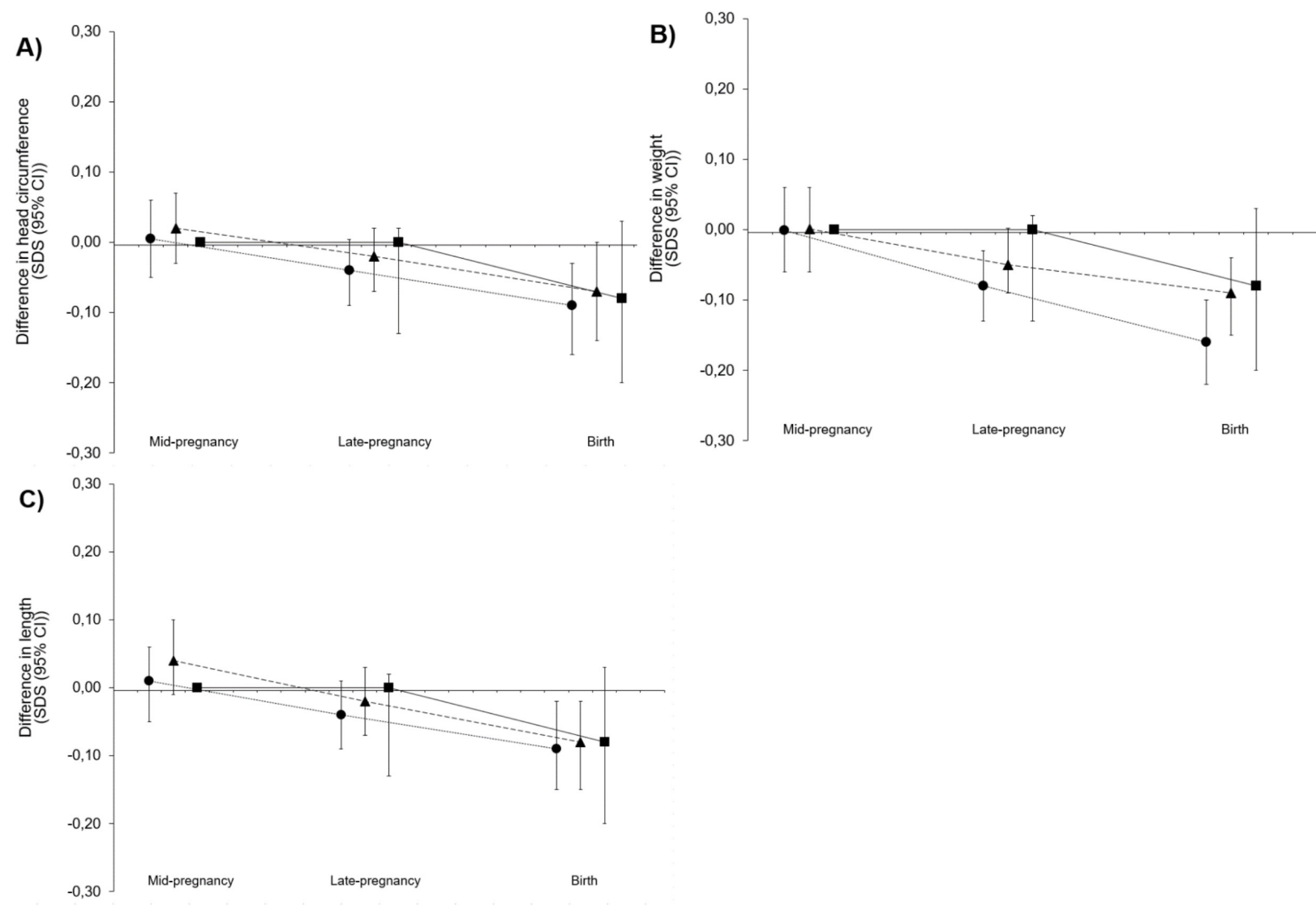

Figure 2 Associations of neighbourhood deprivation with fetal growth. Differences in fetal growth rates for the lower three neighbourhood status score quartiles as compared with the highest neighbourhood status score. Squares represent the lowest quartile of the neighbourhood status score, circles represent the second quartile and triangles the third quartile. Results are based on repeated measurement regression models and reflect the differences in gestational age-adjusted SDS scores of (A) fetal head circumference, (B) weight and (C) length growth for the three lower neighbourhood status score compared with the highest neighbourhood status score (reference group represented as zero line). The models were adjusted for maternal age, educational level, smoking, alcohol use, folic acid supplement use, ethnicity, parity, prepregnancy body mass index and fetal sex. SDS, SD score. 


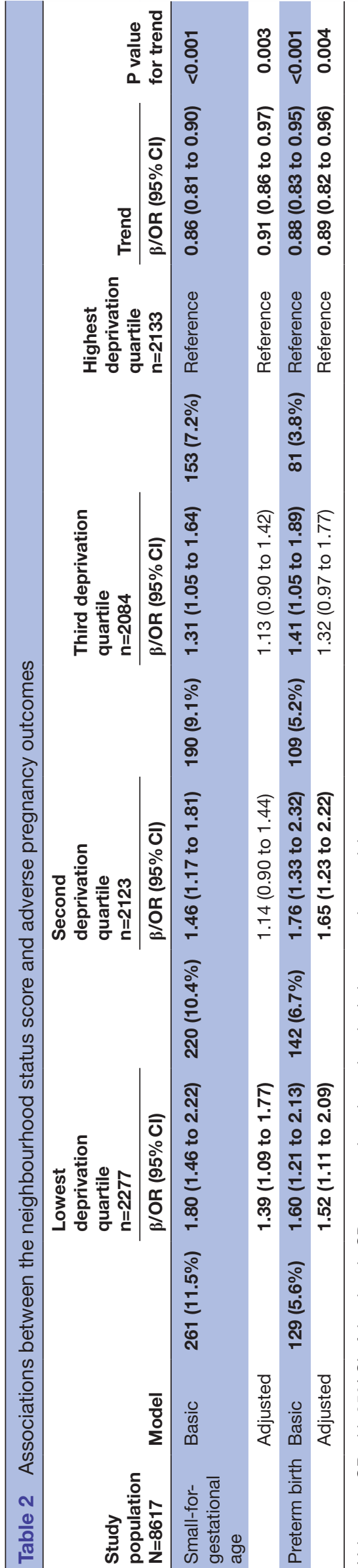

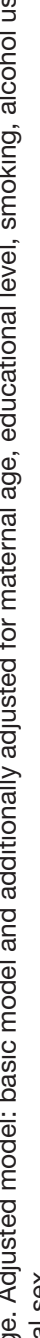

足

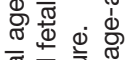

sociodemographic or lifestyle factors. Moreover, it was inversely and independently associated with the odds of PTB (adjusted model, OR 0.89, 95\% CI 0.82 to 0.96 , $\mathrm{p}=0.01$ ). Adverse pregnancy outcomes were most prevalent in the neighbourhood with the lowest deprivation status compared with the neighbourhood with the highest social status (SGA: $12.2 \%$ vs $7.1 \%$; PTB: $5.9 \%$ vs $3.8 \%$ ) (online supplemental table 1).

\section{Sensitivity analyses}

The first sensitivity analysis revealed largely similar associations after performing multilevel analyses (online supplemental figure 2). Second, the results of the associations between neighbourhood deprivation and CRL did not change after including all CRL measurements, in comparison with only the CRL measurements below 12 weeks' gestational age (online supplemental table 5). The third sensitivity analysis excluding SGA pregnancies did attenuate the results (online supplemental table 6). The results also did not materially change after other sensitivity analyses in which we additionally adjusted for household income or adjusted with a different classification of ethnicity (online supplemental tables 7 and 8). The results did not materially change for SGA analyses when adjusting for maternal hypertension in pregnancy (online supplemental table 9). No major differences were observed in confounders before and after multiple imputation (online supplemental table 10).

\section{DISCUSSION \\ Main findings}

We observed that living in a more deprived neighbourhood is associated with decreased fetal growth in the second and third trimesters of pregnancy and with higher odds of SGA birth and PTB.

\section{Strengths and limitations}

The strengths of this study include the large number of participants and the availability of extensive data, which allowed us to adjust for a large number of potential confounders. Its population-based design in a multiethnic population results in a good representation of the residents of the city of Rotterdam. The presence of both residents from deprived and more affluent neighbourhoods in the study population allowed us to investigate the effect of this exposure extensively. The choice of the neighbourhood deprivation indicator is another strength of this study. To classify the degree of neighbourhood deprivation, often composite indexes are used which take into account factors such as the percentage of educated or employed residents and income of residents within a specific neighbourhood. ${ }^{27}$ We selected the status scores of the Netherlands Institute for Social Research because this index is comparable with international indices such as the Index of Multiple Deprivation and the Jarman score. ${ }^{28} 29$ The status scores are a continuous measure, which allows more accurate analyses compared with a dichotomous 
measure. Another strength of the study was that missing data of covariates were handled by applying multiple imputations. In comparison with complete-case analyses (which was conducted as a sensitivity analysis), this technique maintains the statistical power of the analyses.

Some limitations of this study also merit discussion. First, the data with regard to residency and pregnancy are over 15 years old, since the Generation $\mathrm{R}$ study is an ongoing birth cohort. The methods of measuring fetal growth are according to standardised measurement methods, which are still being used. No doubt, there is the possibility that the deprivation status of the neighbourhoods could have changed over time. However, no large differences are to be expected. Additionally, both exposure data (neighbourhood deprivation) and outcome data (fetal growth and pregnancy outcomes) are determined in short succession. Second, we did not use nutritional data from semiquantitative self-administrated Food Frequency Questionnaire (FFQ) since this FFQ is only validated in pregnant women with Dutch ethnic background, which would have diminished the power and external validity of the study. We chose not to adjust for nutritional factors other than alcohol intake and folic acid supplement use since alcohol intake and folic acid supplement use are strongly correlated with other lifestyle and nutritional habits. ${ }^{31}{ }^{31}$ Third, we adjusted the analyses for individual factors to isolate a neighbourhoodspecific effect. However, we cannot rule out the presence of residual confounding caused by other individual factors that are strongly associated with fetal growth. Next, possible misclassification of neighbourhood deprivation may have occurred if women moved during pregnancy to a neighbourhood with a different status score from the one they moved out of. However, social mobility in pregnancy is limited, and if women move they generally tend to move to a neighbourhood with a comparable deprivation status. ${ }^{32}$ Fifth, income of undeclared work is not taken into account in the area-based classification of neighbourhood status scores, while $13 \%$ of Dutch residents do any form of undeclared work. ${ }^{33}$ Sixth, the power of analyses on CRL is lower due to the availability of only one CRL measurement, instead of a repeated assessment of the CRL. A last disadvantage is that participants of cohort studies, even those in more deprived neighbourhoods, generally have a higher level of health awareness and are generally more healthy compared with those who do not participate. ${ }^{13}$ This may reduce the generalisability of our findings to the general population.

Several pathways may explain the disadvantageous effects of living in a deprived neighbourhood on pregnancy ${ }^{34}$ First, it is proposed to be due to the accumulation of risk factors at the individual level. ${ }^{5}$ Examples are smoking and inadequate nutrition and lifestyle behaviours. ${ }^{9}$ Neighbourhood deprivation then acts as a proxy for the increased prevalence of risk factors within the deprived neighbourhoods. Our findings are substantiated by earlier studies within the Generation $\mathrm{R}$ birth cohort which demonstrate that living in a deprived neighbourhood is accompanied by the accumulation of individual-level risk factors. These in turn were associated with adverse pregnancy outcomes. ${ }^{5}$ However, we observe that even after correction for individual-level risk factors, the association between neighbourhood deprivation and impaired development and adverse pregnancy outcomes remained, emphasising an isolated role of neighbourhood deprivation as a risk factor for pregnancy. The associations between neighbourhood deprivation and fetal growth and adverse pregnancy outcomes attenuated to non-significance in the population affected by a complication in a previous pregnancy. These complications, and the maternal constitution for the development of it, may thus outweigh the contribution of neighbourhood deprivation in the associations with fetal growth and adverse pregnancy outcomes. This may be due to the fact that past complications in pregnancy are strongly associated with fetal growth and adverse pregnancy outcomes. ${ }^{35} \mathrm{~A}$ second pathway which may explain the disadvantageous effects of living in a deprived neighbourhood on adverse pregnancy outcomes is attributed to the lack of or suboptimal access to facilities such as the possibility to purchase healthy food nearby. ${ }^{36}$ Third, living in a deprived neighbourhood is acknowledged as a source of chronic stress and thereby acts as an independent risk factor for adverse health outcomes. ${ }^{34}{ }^{37}$ Stress is associated with increased cortisol levels, and both prolonged and repeated cortisol exposures increase the risk of impaired physical health. ${ }^{38}$ Also with regard to pregnancy, stress is demonstrated to be harmful since maternal stress during pregnancy is associated with PTB, lower birth weight, and onset of preeclampsia and gestational diabetes. ${ }^{12} 39$

Our data demonstrate that the associations between neighbourhood deprivation and fetal growth become stronger over the course of pregnancy. This may be due to the fact that there are different mechanisms by which external factors, such as environmental, nutritional and lifestyle factors, affect the developing fetus over the different trimesters of pregnancy. In the first trimester of pregnancy the embryo depends on the uterine glands and yolk sac for provision of nutrients, while in the subsequent periods of pregnancy there is an exchange of nutrients between the maternal and fetal circulations across the placenta. ${ }^{40}$ The more isolated source of nutrition in the first trimester compared with the second and third trimesters of pregnancy may decrease the sensitivity of first trimester embryonic growth to external influences.

A previous study of our group observed a negative association between neighbourhood deprivation and first trimester growth. The larger embryos in deprived neighbourhoods were hypothesised to be explained by strong unmeasured intrinsic and extrinsic factors, such as mental stressors. ${ }^{41}$ The difference in direction of effects between that study and our current findings may be due to the different source populations; the first study was conducted in a tertiary hospital-based cohort, while the present study was performed within a population-based cohort. 


\section{Future perspectives}

In future studies, a potential power issue due to the small measurement differences in first trimester growth may be prevented by using larger study sample sizes. Additionally, animal studies may help unravel the underlying mechanisms through which neighbourhood deprivation affects pregnancy, for instance by further investigating how maternal stress affects placental nutrient transport. Moreover, additional research on the suggested pathways between neighbourhood deprivation and fetal growth and pregnancy outcomes could be performed.

Although the magnitude of our findings is somewhat small, the results of this study suggest an isolated risk of living in a deprived neighbourhood. This emphasises the importance of policies that promote healthier neighbourhoods. This could be achieved by targeted populationlevel interventions. A review has demonstrated many area-based initiatives that have been implemented in deprived areas across Western Europe already. ${ }^{42}$ Initiatives may consist of interventions that aim to tackle the various problems in deprived areas, with regard to the psychical (more walkable neighbourhoods, increasing green environments, reducing air pollution and reduction of litter) and social (lowering crime rates, vandalism) domains. ${ }^{43}$ Small effects of these interventions may be expected in terms of differences in fetal growth and birth weight, although small individual effects may still have clinical and public health relevance, for example, when they affect a large segment of the population, or when a small effect has long-term implications, as is the case with birth weight.

In the Netherlands, in both the prenatal and postnatal setting, screening for non-medical risk factors is starting to become part of daily medical practice. ${ }^{44} 45$ This allows early interventions in order to prevent developmental problems of children in later life. However, we propose a shift of attention towards an earlier window of opportunity: the preconception period and the first trimester of pregnancy. This periconception period provides the opportunity to optimise the conditions of pregnancy and thereby decrease the risks of adverse outcomes and all their long-term consequences. ${ }^{46}$

It is important to create more awareness among politicians, policymakers and public health workers. They could help to embed neighbourhood deprivation in the context of health promotion by developing and promoting targeted preventive intervention programmes. ${ }^{47}$ Additionally, these programmes could specifically focus on residents of deprived neighbourhoods. It is important to stimulate these residents to diminish risk factors on the individual level, for instance to quit smoking and abstain from alcohol. This could also help to narrow health inequalities between neighbourhoods and between groups of different SES.

\section{CONCLUSION}

In conclusion, we observed a negative association between neighbourhood deprivation, fetal growth and prematurity. This emphasises the need for a comprehensive research, care and policy approach from the preconception phase onwards to mitigate the risk of adverse pregnancy outcomes due to deprivation.

Acknowledgements The Generation R study is conducted by the Erasmus Medical Center in close collaboration with the School of Law and the Faculty of Social Sciences at Erasmus University, Rotterdam, the Municipal Health Service, Rotterdam area, and the Stichting Trombosedienst and Artsenlaboratorium Rijnmond (Star-MDC), Rotterdam. We gratefully acknowledge the contribution of the children and their parents, general practitioners, hospitals, midwives and pharmacies in Rotterdam.

Contributors All authors made a substantive contribution to the manuscript. DVG analysed the data and wrote the article. AGP, VWVJ and EAPS contributed to the design of the paper, interpretation of the data and revisions and gave input at all stages of the study. DVG is the guarantor of this work and, as such, had full access to all the data in the study and takes responsibility for the integrity of the data and the accuracy of the data analysis. All authors have approved the final version of the manuscript.

Funding The Generation R study was made possible by financial support from Erasmus MC, University Medical Center Rotterdam, the Netherlands; the Netherlands Organization for Health Research and Development; the Netherlands Organization for Scientific Research; the Ministry of Health, Welfare and Sport; and the Ministry of Youth and Families. VWVJ received additional grants from the Netherlands Organization for Health Research and Development (grants 90700303 and 916.10159, and VIDI 016.136.361) and a Consolidator Grant from the European Research Council (ERC-2014-CoG-64916).

Competing interests None declared.

Patient consent for publication Not required.

Ethics approval The study has been approved by the Medical Ethical Committee of the Erasmus Medical Center in Rotterdam on 17 December 2001 (MEC 198.782/2001/31).

Provenance and peer review Not commissioned; externally peer reviewed.

Data availability statement Data are available upon reasonable request.

Supplemental material This content has been supplied by the author(s). It has not been vetted by BMJ Publishing Group Limited (BMJ) and may not have been peer-reviewed. Any opinions or recommendations discussed are solely those of the author(s) and are not endorsed by BMJ. BMJ disclaims all liability and responsibility arising from any reliance placed on the content. Where the content includes any translated material, BMJ does not warrant the accuracy and reliability of the translations (including but not limited to local regulations, clinical guidelines, terminology, drug names and drug dosages), and is not responsible for any error and/or omissions arising from translation and adaptation or otherwise.

Open access This is an open access article distributed in accordance with the Creative Commons Attribution Non Commercial (CC BY-NC 4.0) license, which permits others to distribute, remix, adapt, build upon this work non-commercially, and license their derivative works on different terms, provided the original work is properly cited, appropriate credit is given, any changes made indicated, and the use is non-commercial. See: http://creativecommons.org/licenses/by-nc/4.0/.

ORCID iD

Dionne V Gootjes http://orcid.org/0000-0002-9382-9031

\section{REFERENCES}

1 Mackenbach JP, Cavelaars AE, Kunst AE, et al. Socioeconomic inequalities in cardiovascular disease mortality; an international study. Eur Heart J 2000;21:1141-51.

2 Pickett KE, Pearl M. Multilevel analyses of neighbourhood socioeconomic context and health outcomes: a critical review. $J$ Epidemiol Community Health 2001;55:111-22.

3 Vos AA, Posthumus AG, Bonsel GJ, et al. Deprived neighborhoods and adverse perinatal outcome: a systematic review and metaanalysis. Acta Obstet Gynecol Scand 2014;93:727-40. 
4 de Graaf JP, Ravelli ACJ, de Haan MAM, et al. Living in deprived urban districts increases perinatal health inequalities. J Matern Fetal Neonatal Med 2013;26:473-81.

5 Timmermans S, Bonsel GJ, Steegers-Theunissen RPM, et al. Individual accumulation of heterogeneous risks explains perinata inequalities within deprived neighbourhoods. Eur J Epidemiol 2011;26:165-80.

6 Mook-Kanamori DO, Steegers EAP, Eilers PH, et al. Risk factors and outcomes associated with first-trimester fetal growth restriction. JAMA 2010;303:527-34.

7 Ashworth CJ, Toma LM, Hunter MG. Nutritional effects on oocyte and embryo development in mammals: implications for reproductive efficiency and environmental sustainability. Philos Trans $R$ Soc Lond B Biol Sci 2009;364:3351-61.

8 Cetin I, Berti C, Calabrese S. Role of micronutrients in the periconceptional period. Hum Reprod Update 2010;16:80-95

9 Van Dijk MR, Borggreven NV, Willemsen SP, et al. Maternal lifestyle impairs embryonic growth: the Rotterdam Periconception cohort. Reprod Sci 2018;25:916-22.

10 Barker DJ. Fetal origins of coronary heart disease. BMJ 1995;311:171-4.

11 Rutter DR, Quine L. Inequalities in pregnancy outcome: a review of psychosocial and behavioural mediators. Soc Sci Med 1990;30:553-68.

12 Vehmeijer FOL, Guxens M, Duijts L, et al. Maternal psychological distress during pregnancy and childhood health outcomes: a narrative review. J Dev Orig Health Dis 2019;10:274-85.

13 Kooijman MN, Kruithof CJ, van Duijn CM, et al. The generation R study: design and cohort update 2017. Eur J Epidemiol 2016;31:1243-64.

14 National Institute for Public Health and the Environment. Sociaaleconomische status, 2017. Available: https://www.volk sgezondheidenzorg.info/onderwerp/sociaaleconomische-status/ regionaal-internationaal/regionaal\#node-sociaaleconomische-status

15 Blaas HG, Eik-Nes SH, Bremnes JB. The growth of the human embryo. A longitudinal biometric assessment from 7 to 12 weeks of gestation. Ultrasound Obstet Gynecol 1998;12:346-54.

16 van Uitert EM, Exalto N, Burton GJ, et al. Human embryonic growth trajectories and associations with fetal growth and birthweight. Hum Reprod 2013;28:1753-61.

17 van der Kooy J, Poeran J, de Graaf JP, et al. Planned home compared with planned Hospital births in the Netherlands: intrapartum and early neonatal death in low-risk pregnancies. Obstet Gynecol 2011;118:1037-46.

18 Poeran J, Borsboom GJJM, de Graaf JP, et al. Population attributable risks of patient, child and organizational risk factors for perinatal mortality in hospital births. Matern Child Health $J$ 2015;19:764-75.

19 Hadlock FP, Harrist RB, Sharman RS, et al. Estimation of fetal weight with the use of head, body, and femur measurements--a prospective study. Am J Obstet Gynecol 1985;151:333-7.

20 Verburg BO, Steegers EAP, De Ridder M, et al. New charts for ultrasound dating of pregnancy and assessment of fetal growth: longitudinal data from a population-based cohort study. Ultrasound Obstet Gynecol 2008;31:388-96.

21 Niklasson A, Ericson A, Fryer JG, et al. An update of the Swedish reference standards for weight, length and head circumference at birth for given gestational age (1977-1981). Acta Paediatr Scand 1991;80:756-62.

22 Verburg BO, Mulder PGH, Hofman A, et al. Intra- and interobserver reproducibility study of early fetal growth parameters. Prenat Diagn 2008;28:323-31.

23 Gaillard R, de Ridder MAJ, Verburg BO, et al. Individually customised fetal weight charts derived from ultrasound measurements: the generation R study. Eur J Epidemiol 2011;26:919-26.

24 Twisk JWR. Applied longitudinal data analysis for epidemiology: a practical guide. 2 ed. Cambridge: Cambridge University Press, 2013.

25 Sterne JAC, White IR, Carlin JB, et al. Multiple imputation for missing data in epidemiological and clinical research: potential and pitfalls. BMJ 2009;338:b2393.
26 Altman DG. Practical statistics for medical research. London, UK: Chapman \& Hall, 1999.

27 Rajaratnam JK, Burke JG, O'Campo P. Maternal and child health and neighborhood context: the selection and construction of area-level variables. Health Place 2006;12:547-56.

28 Noble M, Wright G, Smith G, et al. Measuring multiple deprivation at the Small-Area level. Environ Plan A 2006;38:169-85.

29 Jarman B. Underprivileged areas: validation and distribution of scores. Br Med J 1984;289:1587-92.

30 Kang H-G, Joo HH, Choi KD, et al. Complementarity in dietary supplements and foods: are supplement users vegetable eaters? Food Nutr Res 2017;61:1361769.

31 Kirk SF, Cade JE, Barrett JH, et al. Diet and lifestyle characteristics associated with dietary supplement use in women. Public Health Nutr 1999;2:69-73.

32 Reitsma JB, Kardaun JW, Gevers E. Possibilities for anonymous follow-up studies of patients in Dutch national medical registrations using the Municipal Population Register: a pilot study] Mogelijkheden voor anoniem follow-uponderzoek van patienten in landelijke medische registraties met behulp van de Gemeentelijke Basisadministratie: een pilotonderzoek. Ned Tijdschr Geneeskd 2003;147:2286-90

33 Winden de M Z. Een Onderzoek naar zwartwerk onder uitkeringsgerechtigden en de totale bevolking in 2010. Voorburg/ Heerlen, 2011.

34 de Graaf JP, Steegers EAP, Bonsel GJ. Inequalities in perinatal and maternal health. Curr Opin Obstet Gynecol 2013;25:98-108.

35 Posthumus AG, Birnie E, van Veen MJ, et al. An antenatal prediction model for adverse birth outcomes in an urban population: the contribution of medical and non-medical risks. Midwifery 2016;38:78-86.

36 Agyemang C, Vrijkotte TGM, Droomers M, et al. The effect of neighbourhood income and deprivation on pregnancy outcomes in Amsterdam, the Netherlands. J Epidemiol Community Health 2009;63:755-60.

37 Jokela M. Does neighbourhood deprivation cause poor health? Within-individual analysis of movers in a prospective cohort study. $J$ Epidemiol Community Health 2015;69:899-904.

38 Cohen S, Janicki-Deverts D, Miller GE. Psychological stress and disease. JAMA 2007;298:1685-7.

39 Henrichs J, Schenk JJ, Roza SJ, et al. Maternal psychological distress and fetal growth trajectories: the generation $\mathrm{R}$ study. Psychol Med 2010;40:633-43.

40 Burton GJ, Hempstock J, Jauniaux E. Nutrition of the human fetus during the first trimester--a review. Placenta 2001;22 Suppl A:S70-7.

41 Gootjes DV, Koster MPH, Willemsen SP, et al. The impact of neighbourhood deprivation on embryonic growth trajectories: Rotterdam Periconception cohort. J Clin Med 2019;8. doi:10.3390/ jcm8111913. [Epub ahead of print: 08112019$].$

42 Atkinson. Urban design and planning. , 2008: 161, 115-22.

43 Kramer D, Harting J, Kunst AE. Understanding the impact of area-based interventions on area safety in deprived areas: realist evaluation of a neighbour Nuisance intervention in Arnhem, the Netherlands. BMC Public Health 2016;16:291.

44 Waelput AJM, Sijpkens MK, Lagendijk J, et al. Geographica differences in perinatal health and child welfare in the Netherlands: rationale for the healthy pregnancy 4 all-2 program. BMC Pregnancy Childbirth 2017:17:254.

45 Lagendijk J, Vos AA, Bertens LCM, et al. Antenatal non-medical risk assessment and care pathways to improve pregnancy outcomes: a cluster randomised controlled trial. Eur J Epidemiol 2018;33:579-89.

46 Steegers EAP, Barker ME, Steegers-Theunissen RPM, et al. Societal Valorisation of new knowledge to improve perinatal health: time to act. Paediatr Perinat Epidemiol 2016;30:201-4.

47 van Voorst SF, Vos AA, de Jong-Potjer LC, et al. Effectiveness of general preconception care accompanied by a recruitment approach: protocol of a community-based cohort study (the healthy pregnancy 4 all study). BMJ Open 2015;5:e006284-e. 